AKitomo Matsuki, M.D. ${ }^{*}$ ANd Elemér K. ZsiGmond, M.D. ${ }^{*}$

ON January 28, 1848, only three months after James Young Simpson introduced chloroform in clinical anaesthesia, ${ }^{1}$ the first fatal case due to the inhalation of chloroform occurred in the British Isles." Thereafter, a number of deaths caused by chloroform inhalation occurred in succession. Lyman ${ }^{3}$ stated that between 1848 and 1881, 393 fatal cases occurred during and following the inhalation of chloroform.

This anaesthetic was introduced to Canada in January $1848,4.5$ but ten years elapsed before the first fatality caused by administration of chloroform was reported.

Mr. John McChesney of Toronto went to Dr. French's office to have his teeth extracted on February 1, 1858. The patient was informed about chloroform anaesthesia and he agreed to inhale the agent at his own risk. Then Dr. Richardson, Dr. French's associate, administered the agent by applying a moistened sponge over the nostrils. When the doctor finished extracting six teeth, with some difficulty in the last tooth, the patient was still responsive to vocal orders. Death occurred instantaneously thereafter.

The details are reported in the column of the editorial department of the Medical Chronicle or Montreal Monthly Journal of Medicine and Surgery. ${ }^{6}$

It reads as follows:

\title{
Death from Chloroform
}

A painful feeling was lately occasioned in Toronto by the melancholy death of Mr. John McChesney. This gentleman called at the operating room of Dr. French, surgeon dentist, to have six teeth extracted, but appeared reluctant to submit to the operation unless under the influence of chloroform. Dr. Richardson was accordingly sent for to administer it, which he did, first, however, explaining to Mr. McChesney that he took the anaesthetic solely at his own risk. After a short inhalation, the gums were lanced, and the chloroform having been again applied, the teeth were removed. But as soon as this was done, Mr. McChesney was seen to alter in appearance; his eyes became fixed, the jaws fell, respiration ceased, and the heart action stopped. Every possible attempt was made to restore animation, but to no purpose: Mr. McChesney was dead. Fuller details respecting his death will be found in the evidence below, taken at the inquest held the same evening, 1st February.

Dr. Tobias French, in reply to the foreman of the jury, described the manner in which Dr. Richardson administered the chloroform, by placing it in a sponge and applying it to the nostrils of the patient. After a short time, the patient began to laugh; asked him the cause, and he said he could not help it, seeing those fellows (meaning us) laughing at him. It was then thought he was sufficiently insensible to commence the operation of lancing the gums. He winced under the lancing; I asked him to lean forward and spit into 48104 .

* Department of Anesthesiology, University of Michigan Medical Centre, Ann Arbor, Michigan

Canad. Anaesth. Soc. J., vol. 20, no. 3, May 1973 
the bowl, which he did. He did not speak, but groaned several times. I remarked to the Doctor, that he was getting on well. After a few inhalations, the Doctor said it was better to draw the teeth, and my brother did so. He extracted six. The deceased seemed conscious of pain, and struggled in the drawing of the last tooth, and appeared like a person not fully under the influence. I asked him to lean over the bowl, which I held before him, and he spat into it. I then observed a change pass over his countenance, such as to startle me; and I remarked there was something wrong. Dr. Richardson opened the window, and ordered me to tip the patient on the right side, so that he would not swallow any blood. I next remarked a great change, and exclaimed that he was gone. The deceased at this time looked cadaverous, and his jaw fell. We then took him and laid him on the floor, placed a pillow under his head, and made an application of ammonia; also applied cold water to his head, and had the body briskly rubbed. Dr. Richardson called for assistance and Drs. Russell, Nicholl, Beaumont, and Haswell were brought in. A galvanic battery was also put in operation; but all was of no avail.

Dr. Richardson was examined, and deposed that every precaution was taken in the case of Mr. McChesney, and quoted instances of a similar nature which had taken place in England.

Dr. Haswell.-When I went to Dr. French's I found the deceased lying on the floor. Respiration had then ceased. Dr. Richardson was using efforts to restore animation. I assisted, in conjunction with Drs. Beaumont and Nicholl, for about an hour.

At this stage of the proceedings, it was intimated by the jury that abundant medical testimony had been adduced, and no further evidence was taken.

After a short deliberation, the jury found the following verdict: "That the deceased came to his death in Dr. French's operating room, while under the influence of chloroform, which he had voluntarily inhaled for the purpose of getting some teeth extracted; and that more than ordinary care was used in the administration of the chloroform."

The patient was considered to have no problem immediately before the start of anaesthesia, as Dr. Richardson testified every precaution had been taken in this case. Anaesthesia was not so deep as to lose consciousness completely, and the patient could respond slightly to the doctor's verbal command. Considering these facts, it is most likely that the patient died of sudden cardiac arrest caused by influence of chloroform and not by asphyxia.

As far as the authors know, more than ten chloroform deaths were reported for a period from 1861 to 1897 in Canada. ${ }^{i-17}$

In his paper in 1873 Dr. Coleman ${ }^{18}$ of the Toronto Eye and Ear Infirmary discussed mode of death, causc of death, per cent of fatal cases, condition of patient, sign of danger, methods of administration and rules for administration in rclation to chloroform anaesthesia.

According to the Editorial in the Canada Lancet, 1887,20 the following factors were reported to be the important causes of so-called chloroform death: (i) paralysis of the respiratory center from an overdose; (ii) paralysis of the heart from a too concentrated chloroform vapor; and (iii) a combination of chloroform narcosis and shock.

The editors of the Canada Medical and Surgical Journal ${ }^{20}$ attributed employment of chloroform instead of ether and incorrect resuscitation to the causes of so-called chloroform death.

Chloroform was, however, still a popular inhalational anaesthetic at that time. 


\section{REFERENCES}

1. Simpson, J.Y. On a new anesthetic agent, more efficient than sulphuric ether. Lancet, 2: $349-550$ (1847).

2. Fatal Application of Chloroform. Lancet 1: 161-162 (1848).

3. Lyman, H.M. Artificial anaesthesia and anaesthetics. New York. William Wood and Company, 1881, pp. 136-201.

4. Holmes, A.F. Employment of chloroform. Brit. Amer. J. Med. Phys. Sci. 3: 263-264 (1848).

5. Worthington, E.D. Cases of chloroform. Brit. Amer. J. Med. Phys. Sci. 3: 326-327 (1848).

6. The Medical Chronicle or Montreal Monthly Journal of Medical and Surgery. 5: 425-427 (1858).

7. Roland, C.G. The first death from chloroform at the Toronto General Hospital. Can. Anaes. Soc. J., 11: 437-439 (1964).

8. Canad. Med. J. (Montreal) 3: 380 (1867).

9. Death from chloroform. Canad. Med. Record. 6: 20 (1877-78).

10. Death from chloroform. Canad. Lancet 10: 157 (1878).

11. Death from chloroform. Canad. Lancet 11: 313 (1879).

12. Death from chloroform. Canad. Lancet 12: 157-158 (1880).

13. Another death from chloroform. Canad. Lancet 12: 349 (1880).

14. Gaviller, A.C. The case of sudden death during the first stage of chloroform inhalation. Canad. Lancet 13: 231-232 (1881).

15. LACross, E. Death under chloroform. Montreal Medical J. 19: 919-920 (1881).

16. Death from chloroform. Canad. Lancet 15: 127 (1883).

17. Death from chloroform. Canad. Practioner 18: 309 ( 1893).

18. Coleman, W.S. The administration of chloroform. Canad, Lancet 5: 616-624 (1872-3).

19. Death from chloroform. Canad. Lancet 19: 281-282 (1887).

20. Chloroform deaths. Canad. Medical Surgical J. 16: 248-249 (1887). 